\title{
Selection of N86F184D1246 haplotype of Pfmrd 1 gene by artemether-lumefantrine drug pressure on Plasmodium falciparum populations in Senegal
}

\author{
Aminata Mbaye ${ }^{1 *} \mathbb{0}$, Baba Dieye ${ }^{1}$, Yaye D. Ndiaye ${ }^{1}$, Amy K. Bei ${ }^{1,2}$, Affara Muna ${ }^{4}$, Awa B. Deme ${ }^{1}$, \\ Mamadou S. Yade ${ }^{1}$, Khadim Diongue ${ }^{1}$, Amy Gaye ${ }^{1}$, Ibrahima M. Ndiaye ${ }^{1}$, Tolla Ndiaye ${ }^{1}$, Mouhamad Sy ${ }^{1}$, \\ Mamadou A. Diallo', Aida S. Badiane ${ }^{1}$, Mouhamadou Ndiaye ${ }^{1}$, Mame C. Seck', Ngayo Sy ${ }^{1}$, Ousmane Koita ${ }^{5}$, \\ Donald J. Krogstad ${ }^{3}$, Davis Nwakanma ${ }^{4}$ and Daouda Ndiaye ${ }^{1,2}$
}

\begin{abstract}
Background: The use of artemisinin as a monotherapy resulted in the emergence of artemisinin resistance in 2005 in Southeast Asia. Monitoring of artemisinin combination therapy (ACT) is critical in order to detect and prevent the spread of resistance in endemic areas. Ex vivo studies and genotyping of molecular markers of resistance can be used as part of this routine monitoring strategy. One gene that has been associated in some ACT partner drug resistance is the Plasmodium falciparum multidrug resistance protein 1 (pfmdr1) gene. The purpose of this study was to assess the drug susceptibility of $P$. falciparum populations from Thiès, Senegal by ex vivo assay and typing molecular markers of resistance to drug components of ACT currently used for treatment.
\end{abstract}

Methods: The ex vivo susceptibility of 170 P. falciparum isolates to chloroquine, amodiaquine, lumefantrine, artesunate, and artemether was determined using the DAPI ex vivo assay. The high resolution melting technique was used to genotype the pfmdr1 gene at codons 86, 184 and 1246.

Results: A significant decrease in IC50 values was observed between 2012 and 2013: from 13.84 to 6.484 for amodiaquine, 173.4 to 113.2 for lumefantrine, and 39.72 to 18.29 for chloroquine, respectively. Increase of the wild haplotype NYD and the decrease of the mutant haplotype NFD (79 and 62.26\%) was also observed. A correlation was observed between the wild type allele Y184 in pfmdr1 and higher IC50 for all drugs, except amodiaquine.

Conclusion: This study has shown an increase in sensitivity over the span of two transmission seasons, marked by an increase in the WT alleles at pfmdr1. Continuous the monitoring of the ACT used for treatment of uncomplicated malaria will be helpful.

Keywords: Plasmodium falciparum, Haplotype, Artemether-lumefantrine, pfmdr1, Senegal

\section{Background}

Among the five species of Plasmodium causing human malaria, Plasmodium falciparum is the deadliest. The latest World Malaria Report showed that of the 214 million

\footnotetext{
*Correspondence: aminatambaye155@gmail.com

${ }^{1}$ Laboratory of Parasitology/Mycology HALD, Cheikh Anta Diop University of Dakar, PO Box 5005, Dakar, Senegal

Full list of author information is available at the end of the article
}

cases of malaria recorded in 2014, $88 \%$ were registered in sub-Saharan Africa where most of cases were caused by P. falciparum $[1,2]$.

In the late 1950s, resistance of $P$. falciparum to chloroquine (CQ) emerged in South America and Southeast Asia [3]; since then, resistance has spread rapidly around the world and in Africa the first cases were reported in 1978 [4]. The introduction of other 
anti-malarial drugs [sulfadoxine-pyrimethamine (SP), mefloquine (MQ), etc.] has led to the emergence of strains of $P$. falciparum that are resistant to multiple drugs in some endemic areas [5]. As a result, since April 2001, the World Health Organization (WHO) has recommended the use of artemisinin-based combination therapy (ACT) in countries where $P$. falciparum is resistant to $\mathrm{CQ}, \mathrm{SP}$, and amodiaquine (AMQ), to avoid early emergence of resistance to these molecules [6]. Despite these efforts, cases of resistance to artemisinin (ART) have emerged in Cambodia and in other regions of Southeast Asia [7]. Indeed, in these countries, ART was used as monotherapy for uncomplicated falciparum malaria. Monitoring the sensitivity of $P$. falciparum to ACT becomes essential for therapeutic management of malaria. Such monitoring can be done by various methods, including in vivo efficacy studies, in vivo clearance time assays [8], in vitro chemo-sensitivity to anti-malarial drugs (RSA), and genotyping of pfk13 molecular markers of ART resistance [9]. For the P. falciparum multidrug-resistant protein 1 ( $p f m d r 1$ ) gene, several single nucleotide polymorphisms were described, but the more common were N86Y, Y184F, S1034C, N1042D, and D1246Y. Studies have shown an association of $p f m d r 1$ gene, specifically the codon 86 , and a decrease of sensitivity to AMQ and artesunate (ARS) $[10,11]$. Studies have also shown the $86 \mathrm{Y}$ and $1246 \mathrm{Y}$ mutations are strongly related to the reduction of in vivo sensitivity to artesunate-amodiaquine combination (ASAQ). Also, the N86 and D1246 alleles are related to a decrease of susceptibility to artemetherlumefantrine combination (AL) [12-14]. Moreover, the haplotype N86F184D1246 is selected by a high drug pressure of AL $[15,16]$, while 1034C, 1042D and $1246 \mathrm{Y}$ mutations have been reported to confer resistance against quinine $(\mathrm{QN})$ and increased susceptibility to MQ, halofantrine (HF) and ART $[17,18]$.

In Senegal, ACT has been implemented as first-line treatment for uncomplicated falciparum malaria since 2006, following WHO recommendation [19]. AL and ASAQ combination are used for first-line treatment of uncomplicated $P$. falciparum malaria [2]. Ex vivo studies have been conducted to study the sensitivity of current anti-malarial drugs used against circulating $P$. falciparum populations in Senegal [20-23]. This work aims to study the consequences of use of ACT (ASAQ and AL) for uncomplicated malaria treatment in Senegal by using the ex vivo sensitivity to ARS, AMQ, artemether (AMT) and lumefantrine (LUM) of $P$. falciparum isolates from Thiès collected during the transmission period of malaria combined to the $p f m d r 1$ gene polymorphism at codon N86Y, N184F and D1246Y.

\section{Methods}

\section{Study sites}

Patient recruitment took place during the seasonal malaria period (from September to December) in Section de Lutte Anti-Parasitaire (SLAP) clinic in Thiès in 2012 and 2013. This centre has the privilege to control malaria treatment in Thiès region. The epidemiological profile of this region is characterized as sahelian with a short, seasonal transmission period, generally fewer than 4 months after the rainy season ends. The vectors found are Anopheles arabiensis and Anopheles gambiae and the entomological inoculation rate is generally low and varies from 1 year to another (0-20 infectious bites/person/ year). The region of Thiès is located at $70 \mathrm{~km}$ from Dakar and malaria incidence in this region ranges between five and 15 per 1000 inhabitants [21, 24].

Individuals who presented at the health centre with malaria symptoms were tested by both microscopy and rapid diagnostic test (when available). The selected patients, aged from 5 to 20 years, had uncomplicated malaria due to $P$. falciparum with a parasitaemia higher than $15,000 \mu \mathrm{l}$. Exclusion criteria included individuals who had clinical features of severe malaria or who had a history of taking anti-malarial treatment prior to the visit. Informed consent or assent of the patient and their guardian (for children) was obtained before collecting the blood. The Human Subjects Committee of Tulane University and the Ethics Committee of the Senegal Ministry of Health in Dakar both approved the protocols used in these studies. The work was supported by the International Centres of Excellence for Malaria Research, (ICEMR) West Africa (U19AI089696).

\section{Blood sample collection}

Venous blood was collected in EDTA tubes and filter papers were collected by finger prick. Patients were treated with AMT-LUM or ARS-AMQ combination. These samples were sent to Aristide Le Dantec Hospital within $6 \mathrm{~h}$ of blood draw.

\section{Drugs and drug preparation}

AMQ hydrochloride (USP), ARS (Sigma), AMT (SIGMA), CQ diphosphate (Sigma) and LUM (USP) were used in ex vivo assays. These molecules were dissolved directly in dimethyl sulfoxide (DMSO) solvent at a concentration of $10 \mathrm{mM}$. A first dilution (1/1000) with RPMI 1640 media was done to obtain an intermediate solution. A serial dilution (1/2) was then operated to get a range of concentrations for each drug. The range of concentration varied from 100 to $0.39 \mathrm{nM}$ for AMQ, 75 to $0.29 \mathrm{nM}$ for ARS, 150 to $0.58 \mathrm{~nm}$ for AMT, 750 to $2.93 \mathrm{nM}$ for CQ, and 2000 to $7.81 \mathrm{nM}$ for LUM. The 96-well plates were 
then loaded with drugs at a final volume $20 \mu \mathrm{l}$ per well and stored at $-20{ }^{\circ} \mathrm{C}$ until use.

\section{Ex vivo assay}

Parasitized blood samples from the field were first centrifuged to remove the plasma, then washed two times with unsupplemented media. Samples with a parasitaemia between 0.4 and $1 \%$ were suspended in complete media, supplemented with $\mathrm{AB}$ serum and Albumax II to adjust the haematocrit to $2 \%$ before being distributed into 96-well plates preloaded with drugs. If parasitaemia was higher than $1 \%$, a dilution with an $\mathrm{O}+$ blood sample without $P$. falciparum strains was done. The plates were incubated at $37{ }^{\circ} \mathrm{C}$ under the following gas conditions $\left(1 \% \mathrm{O}_{2}, 5 \% \mathrm{CO}_{2}\right.$ and $\left.94 \% \mathrm{~N}_{2}\right)$ for 48 or $72 \mathrm{~h}$, until parasite re-invasion as assessed by microscopy. The ex vivo response of parasites to the different anti-malarial drugs was evaluated using the DAPI molecular probe as described previously [25]. Plates were briefly thawed, spun, and re-suspended with $100 \mu \mathrm{l}(3.64 \mathrm{nM}$ of DAPI concentration) of DAPI-buffer and incubated for $30 \mathrm{~min}$ in the dark. They were washed with the PBS before reading at excitation wavelength of $358 \mathrm{~nm}$ and emission wavelength of $460 \mathrm{~nm}$ using a Fluoroskan Ascent reader. Percent growth was calculated relative to the RPMI-only control wells for each plate. The control strain used to validate results was sensitive to CQ $P$. falciparum 3D7 laboratory strain from MR4.

\section{DNA extraction and genotyping}

The genomic DNA was extract from filter papers using the QIAmp DNA mini kit (Qiagen) following manufacturer's instructions. The high resolution melting (HRM) technique was used for genotyping codons N86Y, Y184F and D1246Y of pfmdr1 gene and codon K76T of pfcrt using specific primers and probes, as previously described [26].

\section{Statistical analysis}

All statistical analyses were performed using Graph Pad Prism software (Version 5.0). Mann-Whitney test was used to compare the distribution of IC50 s between years. For the difference of $p f m d r 1$ polymorphism, the online $\mathrm{Z}$ test for two populations' proportion was used. $p$ value was considered significant when it was less than 0.05 .

\section{Results}

\section{Ex vivo susceptibility of Plasmodium falciparum parasites from Thiès}

Among a total of 120 and 50 samples collected, respectively, in 2012 and 2013 in Thiès, 114 and 48, respectively, were tested. The eight non-tested samples had a parasitaemia lower than 15,000 parasites/ $\mu \mathrm{l}$.

Parasites' responses to drugs at Thiès in 2012 and 2013 are listed in Table 1. Ex vivo result was validated by testing the 3D7 strain sensitive to $\mathrm{CQ}$ and good sensitivity was found with a significant increase. The geometric mean of IC50 values reported in 2012 and 2013 were, respectively, 13.84 and $6.484 \mathrm{nM}(\mathrm{p}<0.0001)$ for AMQ; 173.4 and $113.2 \mathrm{nM}$ ( $\mathrm{p}=0.01$ ) for LUM; 3.322 and $3.673 \mathrm{nM}$ ( $\mathrm{p}=0.34$ ) for ARS; 39.72 and $18.29 \mathrm{nM}$ ( $<<0.0001)$ for CQ. AMT was only tested in 2013, the geometric mean found was $6.222 \mathrm{nM}$.

\section{Polymorphism assessment of pfmdr 1 and pfcrt genes and haplotype of $m d r 1$ gene analysis}

The 120 and 50 samples collected in Thiès were successfully genotyped. The majority of isolates had the wild type alleles $\mathrm{N}$ and $\mathrm{K}$ at codon 86 (pfmdr1) and 76 (pfcrt) with respectively 96 and $78 \%$ in 2012 and 98 and $80 \%$ in 2013. Mixed allele was found in 2012 in $1 \%$ for N86Y and $2 \%$ for K76T of proportion. The mutant allele for these codons was in proportion of 3 and $2 \%$ in 2012 and 2 and $0 \%$ in 2013. Concerning the 184 codon, the mutant allele F predominates both in the 2 years with $75 \%$ for $\mathrm{F}$

Table 1 Ex vivo susceptibility of Plasmodium falciparum isolates from Thiès in 2012 and 2013

\begin{tabular}{|c|c|c|c|c|c|c|c|c|c|}
\hline \multirow[t]{3}{*}{ Drug } & \multicolumn{4}{|l|}{2012} & \multicolumn{4}{|l|}{2013} & \multirow[t]{3}{*}{$p$ value } \\
\hline & \multirow{2}{*}{$\begin{array}{l}\text { 3D7 IC50 } \\
(\mathrm{nM})\end{array}$} & \multirow{2}{*}{$\begin{array}{l}\text { Mean with } 95 \% \text { IC } \\
\text { (nM) }\end{array}$} & \multicolumn{2}{|c|}{ Range (nM) } & \multirow{2}{*}{$\begin{array}{l}\text { 3D7 IC50 } \\
(\mathrm{nM})\end{array}$} & \multirow{2}{*}{$\begin{array}{l}\text { Mean with } 95 \% \text { IC } \\
\text { (nM) }\end{array}$} & \multicolumn{2}{|c|}{ Range (nM) } & \\
\hline & & & Min & $\operatorname{Max}$ & & & Min & $\operatorname{Max}$ & \\
\hline $\mathrm{AMQ}$ & 5.488 & $13.84(11.84-16.13)$ & 0.7425 & 63.13 & 3.321 & $6.484(5.208-8.071)$ & 1.925 & 43.85 & $<0.0001$ \\
\hline LUM & 417.5 & $173.4(142.0-211.8)$ & 21.26 & 981.1 & 164.3 & $113.2(85.9-149.1)$ & 17.05 & 414 & 0.01 \\
\hline ARS & 17.88 & $3.322(2.852-3.869)$ & 0.5222 & 10.16 & 2.805 & $3.673(3.046-4.428)$ & 1.22 & 18.54 & 0.34 \\
\hline AMT & & - & - & - & 7 & $6.222(5.013-7.724)$ & 1.188 & 33.6 & - \\
\hline CQ & 17.58 & $39.72(30.92-51.02)$ & 2.850 & 402.9 & 9.287 & 18.29 (29.07-87.59) & 6.474 & 384.1 & $<0.0001$ \\
\hline
\end{tabular}

The chloroquine-sensitive strain 3D7 was tested and gave adequate results $<100 \mathrm{nM}$ [44]. The difference of values for each molecule for 3D7 was significant excepted for artesunate $(p=0.35)$. $p$ value indicates the significance of the difference of geometric means of the same molecule between 2012 and 2013 
allele (vs. $20 \%$ for Y allele) in 2012 and $60 \%$ for F allele (vs. $34 \%$ for Y allele) in 2013 with a significant difference $(\mathrm{p}=0.029)$. The presence of mixed allele in Thiès isolates (3\% in 2012 and $6 \%$ in 2013) for this codon was noted. Finally, for 1246 codon, the only allele found was the wild type D1246 (Table 2).

Samples containing single allele in the codons N86Y and Y184F were used to determine prevalence of the circulating $p f m d r 1$ to reduce ambiguity from the mixed samples. The haplotypes N86Y184D1246, N86F184D1246 and Y86F184D1246 were found both in 2012 and 2013 (Table 2). A high prevalence of N86F184D1246 haplotype was found $79 \%$ in 2012 and $62.26 \%$ in 2013 with a significant decrease in 2013.

Both the wildtype Y184 and the combined N86Y184D1246 are selected in 2013.

\section{Genotype and phenotype analysis}

An association analysis between 184F mutation and the ex vivo susceptibility to LUM, AMT, CQ, AMQ, and ARS was performed (Table 3). High geometric means of IC50 for LUM were found with samples having the wild allele Y184 in 2012 isolates ( $p=0.0008$ ). For the other compounds, no difference between the geometric mean of IC50 of isolates with the 184F allele and that of GM of IC50 $\mathrm{s}$ with the wild allele was see.

\section{Discussion}

Plasmodium falciparum resistance exists to all first-line anti-malarial drugs, used in both the past and present, alarmingly, even artemisinin derivatives. This resistance has been confirmed in five countries in Southeast Asia (Cambodia, The Lao People's Democratic Republic, Myanmar, Thailand, Viet Nam) [27]. Monitoring ACT

Table 2 Prevalence of single nucleotide polymorphism et haplotypes of pfmdr1 gene of isolates from Thiès

\begin{tabular}{llll}
\hline pfmdr1 genotype & $\mathbf{2 0 1 2 ( 1 2 0 )}$ & $\mathbf{2 0 1 3}(\mathbf{N}=\mathbf{5 0})$ & p value \\
\hline N86 & $97 \%(84 / 87)$ & $98 \%(49 / 50)$ & 0.63 \\
$86 Y$ & $2 \%(2 / 87)$ & $2 \%(1 / 50)$ & 0.1151 \\
MIXTE (N86Y) & $1 \%(1 / 87)$ & $0 \%$ & 0.44 \\
Y184 & $20 \%(22 / 119)$ & $34 \%(17 / 50)$ & 0.029 \\
184F & $78 \%(93 / 119)$ & $60 \%(30 / 50)$ & 0.0155 \\
MIXTE (Y184F) & $3 \%(4 / 119)$ & $6 \%(3 / 50)$ & 0.42 \\
D1246 & $100 \%(119 / 119)$ & $100 \%(50 / 50)$ & - \\
K76 & $78 \%(47 / 60)$ & $80 \%(40 / 50)$ & 0.83 \\
76T & $20 \%(12 / 60)$ & $20 \%(10 / 50)$ & 1 \\
MIXTE & $2 \%(1 / 60)$ & $0 \%$ & 0.36 \\
NYD & $18 \%(18 / 102)$ & $35.85 \%(18 / 50)$ & 0.012 \\
NFD & $79 \%(81 / 102)$ & $62.26 \%(31 / 50)$ & 0.022 \\
YFD & $3 \%(3 / 102)$ & $1.89 \%(1 / 50)$ & 0.72 \\
\hline
\end{tabular}

Table 3 Association between the mutation $184 \mathrm{~F}$ and the geometric means of IC50 values for each drugs

\begin{tabular}{lllll}
\hline Drugs & Year & \multicolumn{3}{l}{ IC50 geometric mean (nM) } \\
\cline { 3 - 5 } & & Y184 & $\mathbf{1 8 4 F}$ & p value \\
\hline Amodiaquine & 2012 & $10.51(19)$ & $15.02(69)$ & 0.0671 \\
& 2013 & $5.1(16)$ & $6.277(24)$ & 0.1992 \\
Chloroquine & 2012 & $117.8(20)$ & $104(89)$ & 0.1094 \\
& 2013 & $24.18(15)$ & $28.10(27)$ & 0.1036 \\
Lumefantrine & 2012 & $493.6(15)$ & $179.2(69)$ & 0.0008 \\
& 2013 & $155.9(15)$ & $68.13(23)$ & 0.1277 \\
Artesunate & 2012 & $4.034(12)$ & $3.041(60)$ & 0.3808 \\
& 2013 & $3.365(17)$ & $3.693(25)$ & 0.5729 \\
Artemether & 2012 & - & - & - \\
& 2013 & $5.997(17)$ & $5.936(25)$ & 0.9387
\end{tabular}

The numbers in parentheses indicate the number of samples with wild or mutant allele

resistance worldwide is absolutely essential, as there is no other alternative drug treatment available [28].

In Senegal, ACT has been first-line treatment since 2006, and currently, AL and ASAQ are recommended as first-line treatment of uncomplicated malaria, while dihydroartemisinin-piperaquine is used as second-line [2, 19]. Both combinations (AL and ASAQ) are effective event for child and adult [29]. However, AL is used more frequently because it is better tolerated [30]. ACT treatment failure of $0.9 \%$ for AL was observed between 2004 and 2014 and it was $0.25 \%$ for ASAQ treatment [2]. Previous studies showed that AL, DHAPQ and ASAQ are highly effective for the treatment of uncomplicated $P$. falciparum malaria in Senegal [31, 32]. In Thiès (2012-2013) three recrudescent samples were observed and these did not reveal mutation in the K13 propeller region (Dieye et al. pers. comm.).

The DAPI ex vivo test, that has been shown to be an excellent technique to study the chemo-sensitivity of $P$. falciparum [20, 25], was used to measure the ex vivo sensitivity of isolates from Thiès in 2012 and 2013 to AMQ, CQ, LUM, ARS, and AMT. Currently, novel phenotype assays (RSA) and a new molecular maker of mutations in the kelch 13 (K13) propeller region [9], to detect resistance of ART derivatives, are used and recommended [33-35]. However, in this study, the data presented was manipulated in the seasonal period of 2012 and 2013, before the RSA recommendation in December 2013. Kelch 13 sequencing was performed and no mutations known to confer resistance were observed in these samples (Deme \& Ndiaye, pers. comm).

To validate the result, 3D7 chloroquine sensitive strain was used. Good sensitivity ( $<00 \mathrm{nM}$ ) was found for chloroquine in both years. A significant increase of sensitivity 
was observed for 3D7 and isolate from Thiès and this, for all molecules except artesunate, which means the differences in drugs between years could be for technical reasons rather than biological ones. ARS and AMT exert their actions through formation of dihydroartemisinin in vivo [36]. This metabolite is often present in higher concentrations than the parent drugs. However, studies show that AMT and ARS have potent parasite killing activity in vitro [37]. This id why AMT and ARS were tested separately.

Also, five single nucleotide polymorphisms in the $p f m d r 1$ gene were associated to anti-malarial drug resistance. Studies show that the $p f m d r 1$ gene polymorphism at codons N86Y, Y184F and D1246Y is mainly linked to AL or ASAQ drug pressure $[15,38,39]$. These facts justify the choice of the three codons of $p f m d r 1$ gene.

The resistance to AMQ has always been linked to the mutation at the 86 position of the pfmdr1 gene $[10,11]$. Studies show that high ASAQ pressure on the parasite population can select Y86Y184Y1246 haplotypes [15]. The existence of cross resistance, strains resistance to both of drugs together, between AMQ and CQ was detected [40]. The result obtained in Thiès, combined with those obtained in the same region in 2010 [25] and in 2013 [20] reveal that the ex vivo sensitivity of the parasite population to AMQ and CQ has increased between 2011 and 2013. Also, as previously described in Thiès [20], a decrease of the mutation at the 86 position was observed. Studies show that the prevalence of $86 \mathrm{Y}$ allele increased between 2000 and 2003 on parasites from Pikine (Dakar). However, a decrease was noted between 2003 and 2009 in this locality [41]. These results reveal that sensitivity of parasite to AMQ increased drastically after the abandonment of chloroquine in 2003. The same tendency was observed in Thiès. Also, for the Pfmdr1 gene, the haplotype Y86Y184Y1246 was not found. This means that the drugs ARS and AMQ are effective on the population of $P$. falciparum from Thiès and any drug pressure was noted. Increase of wild-type allele K76 was also found between 2011 and 2013 in Thiès. The study of Ndiaye et al. [42] also showed this increase in the central (70.5\% in 2009 and $74.8 \%$ in 2010) and in southern (65.4\% in 2010 and $71.0 \%$ in 2011) Senegal.

The combination AMT-LUM has been used as firstline treatment for uncomplicated malaria in Senegal since 2006 [43]. The resistance to LUM has been linked to the increase of copy number in the $p f m d r 1$ gene and the selection of the N86 allele [10]. However, studies have shown a selection of the N86F184D1246 haplotype by a high pressure of AL $[12,16]$. The high prevalence of wild allele N86, mutant allele 184F and N86F184D1246 haplotype was also noted in this study. In Thiès, Van Tyne et al. [20] demonstrated an increase of the $184 \mathrm{~F}$ mutation between 2008 and 2011. However, a tendency to a decrease of this mutation between 2011 and 2013 was noted. This tendency can be explained by the use of the ASAQ combination in SLAP (health centre) after the unavailability of AL. This observation means that a pressure is exerted by AMT-LUM combination on the parasite population from Thiès and then this pressure decreases if the drug (AL) is not used.

\section{Conclusion}

The study of ex vivo sensitivity of $P$. falciparum to antimalarial drugs is a powerful tool to understand parasite phenotypes and to orient the policy of monitoring therapeutic management of malaria. The results of this study show a good sensitivity of $P$. falciparum populations to amodiaquine, artesunate, artemether and lumefantrine. So, the high prevalence of N86F184D1246 haplotype selected by AL pressure was found. Expanded in vivo surveillance of ACT and continued monitoring of artemisinin drug resistance by using new techniques, such as the ex vivo RSA and kelch13 genotyping, should be a priority.

\section{Authors' contributions}

$A M, B D, Y D N, A B D, M S Y, A G, I M N, T N, A S B, M A D, M N, M C S, M A$ and $A K B$ carried out the experiments and collected data. NS, DN, DJK, OK, DN conceived and designed the study. AM and AKB analysed the data. AM, BD, KD, ABD and YDN wrote the manuscript. All authors read and approved the final manuscript.

\section{Author details \\ ${ }^{1}$ Laboratory of Parasitology/Mycology HALD, Cheikh Anta Diop Univer- sity of Dakar, PO Box 5005, Dakar, Senegal. ${ }^{2}$ Department of Immunology and Infectious Diseases, Harvard School of Public Health, Boston, MA, USA. ${ }^{3}$ Tulane University, New Orleans, LA, USA. ${ }^{4}$ Malaria Research Centre, Ser- rekunda, Gambia. ${ }^{5}$ University of Bamako, Bamako, Mali.}

\section{Acknowledgements}

We acknowledge the International Center for Excellence in Malaria Research (ICEMR) project. We thank Cyrille Diedhiou, Nasserdine Papa Nze, Dior Diop, Younouss Diedhiou, Lamine Ndiaye, Amadou Mactar Mbaye, the SLAP patients and staff for their contribution in this study.

\section{Competing interests}

The authors declare that they have no competing interests.

\section{Consent for publication}

The participants in this study are consent for publication.

\section{Ethics approval and consent to participate}

The Human Subjects Committee of Tulane University and the Ethics Committee of the Senegal Ministry of Health in Dakar both approved the protocols used in these studies.

\section{Funding}

The work was supported by the International Centers of Excellence for Malaria Research, (ICEMR) West Africa (U19AI089696).

Received: 9 June 2016 Accepted: 16 August 2016

Published online: 25 August 2016 


\section{References}

1. WHO. Q\&A on artemisinin resistance. Geneva, World Health Organization. 2013 http://who.int/malaria/media/artemisinin_resistance_qa/en/.

2. WHO. World Malaria Report. Geneva, World Health Organization. 2015 http://apps.who.int/iris/bitstream/10665/200018/1/9789241565158_eng. pdf

3. Blount RE. Management of chloroquine resistant falciparum malaria. Trans Am Clin Climatol Assoc. 1967;78:196-204.

4. Kihamia CM, Gill HS. Chloroquine-resistant falciparum malaria in semiimmune native African Tanzanians. Lancet. 1982;2:43.

5. Anderson TJ, Roper C. The origins and spread of antimalarial drug resistance: lessons for policy makers. Acta Trop. 2005;94:269-80.

6. WHO. Briefing on malaria treatment guidelines and artemisinin monotherapies. Geneva, World Health Organization. 2006. http://apps.who.int/ malaria/docs/Meeting_briefing19April.pdf.

7. Noedl H, Se Y, Schaecher K, Smith BL, Socheat D, Fukuda MM. Evidence of artemisinin-resistant malaria in western Cambodia. N Engl J Med. 2008;359:2619-20.

8. WHO. Global report on antimalarial drug efficacy and drug resistance: 2000-2010. Geneva: World Health Organization; 2010.

9. Ariey F, Witkowski B, Amaratunga C, Beghain J, Langlois AC, Khim N, et al. Molecular marker of artemisinin-resistant Plasmodium falciparum malaria. Nature. 2014;505:50-5.

10. Pradines $B$, Dormoi J, Briolant $S$, Bogreau H, Rogier C. La résistance aux antipaludiques. Revue Francophone des Laboratoires. 2010; 422.

11. Eyase FL, Akala HM, Ingasia L, Cheruiyot A, Omondi A, Okudo C, et al. The role of Pfmdr1 and Pfcrt in changing chloroquine, amodiaquine, mefloquine and lumefantrine susceptibility in Western-Kenya P. falciparum samples during 2008-2011. PLoS One. 2013;8:e64299.

12. Kavishe RA, Paulo P, Kaaya RD, Kalinga A, Van Zwetselaar M, Chilongola J, et al. Surveillance of artemether-lumefantrine associated Plasmodium falciparum multidrug resistance protein-1 gene polymorphisms in Tanzania. Malar J. 2014:13:264

13. Ashley E, Dhorda M, Fairhurst RM, Amaratunga C, Lim P, Suon S, Sreng S, et al. Spread of artemisinin resistance in Plasmodium falciparum malaria. N Engl J Med. 2014;371:411-23.

14. Sisowath C, Petersen I, Veiga MI, Mårtensson A, Björkman A, Fidock DA, Gil JP. In vivo selection of Plasmodium falciparum parasites carrying the chloroquine-susceptible pfcrt K76 allele after treatment with artemetherlumefantrine in Africa. J Infect Dis. 2009:199:750-7.

15. Baliraine FN, Rosenthal PJ. Prolonged selection of pfmdr1 polymorphisms after treatment of falciparum malaria with artemether-lumefantrine in Uganda. J Infect Dis. 2011;204:1120-4.

16. Happi CT, Gbotosho GO, Folarin OA, Sowunmi A, Hudson T, O'Neil M, et al. Selection of Plasmodium falciparum multidrug resistance gene 1 alleles in asexual stages and gametocytes by artemether-lumefantrine in Nigerian children with uncomplicated falciparum malaria. Antimicrob Agents Chemother. 2009;53:888-95.

17. Humphreys GS, Merinopoulos I, Ahmed J, Whitty CJM, Mutabingwa TK, Sutherland CJ, et al. Amodiaquine and artemether-lumefantrine select distinct alleles of the Plasmodium falciparum mdr1 gene in Tanzanian children treated for uncomplicated malaria. Antimicrob Agents Chemother. 2007:51:991-7.

18. Jacqueline K, Lekostaj L, Amoah E, Roepe PD. A single S1034C mutation confers altered drug sensitivity to PfMDR1 ATPase activity that is characteristic of the 7G8 isoform. Mol Biochem Parasitol. 2008;157:107-11.

19. PNLP. Directives nationales de prevention et de prise en charge du paludisme. Dakar. 2013-24. http://www.asgosenegal.org/docs/DirectivesPECVFF.pdf.

20. Van Tyne D, Dieye B, Valim C, Daniels RF, Sène PD, Lukens AK, et al. Changes in drug sensitivity and anti-malarial drug resistance mutations over time among Plasmodium falciparum parasites in Senegal. Malar J. 2013;12:441.

21. Ndiaye D, Dieye B, Ndiaye YD, Tyne DV, Daniels R, Bei AK, et al. Polymorphism in dhfr/dhps genes, parasite density and ex vivo response to pyrimethamine in Plasmodium falciparum malaria parasites in Thies, Senegal. Int J Parasitol Drugs Drug Resist. 2013;3:135-42.

22. Fall B, Camara C, Fall M, Nakoulima A, Dionne P, Diatta B, et al. Plasmodium falciparum susceptibility to standard and potential anti-malarial drugs in Dakar, Senegal, during the 2013-2014 malaria season. Malar J. 2015;14:60.
23. PNLP. Plan Stratégique National 2011-2015. Dakar. 2010-129. http://www.africanchildforum.org/clr/policypercountry/senegal/ senegal_malaria_2011-2015_fr.pdf.

24. PNLP. Bulletin épidémiologique annuel du paludisme au Senegal. Dakar. 2014-24. http://www.pnlp.sn/telechargements/Rapports/Bulletin-Epidemiologique-Annuel-2014-du-Paludisme-au-Senegal.pdf.

25. Ndiaye D, Patel V, Demas A, LeRoux M, Ndir O, Mboup S, et al. A non-radioactive DAPI-based high-throughput in vitro assay to assess Plasmodium falciparum responsiveness to antimalarials -increased sensitivity of $P$. falciparum to chloroquine in Senegal. Am J Trop Med Hyg. 2010;82:228-30.

26. Daniels R, Ndiaye D, Wall M, McKinney J, Séne PD, Sabeti PC, et al. Rapid, field-deployable method for genotyping and discovery of single-nucleotide polymorphisms associated with drug resistance in Plasmodium falciparum. Antimicrob Agents Chemother. 2012;56:2976-86.

27. WHO. Status report on artemisinin resistance. Geneva: World Health Organization; 2014

28. Ménard D, Ariey F, Mercereau-Puijalon O. Étude de la résistance de Plasmodium falciparum aux antipaludiques au sein du réseau international des Instituts Pasteur. Med Sci (Paris). 2013;29:647-55.

29. Ndiaye JL, Randrianarivelojosia M, Sagara I, Brasseur P, Ndiaye I, Faye B, et al. Randomized, multicentre assessment of the efficacy and safety of ASAQ-a fixed-dose artesunate-amodiaquine combination therapy in the treatment of uncomplicated Plasmodium falciparum malaria. Malar J. 2009;8:125

30. Maiteki-Sebuguzi C, Jagannathan P, Yau VM, ClarkTD, Njama-Meya D, et al. Safety and tolerability of combination antimalarial therapies for uncomplicated falciparum malaria in Ugandan children. Malar J. 2008;7:106

31. Sylla K, Abiola A, Tine R, Faye B, Sow D, Ndiaye JL, et al. Monitoring the efficacy and safety of three artemisinin-based combinations therapies in Senegal: Results from two years surveillance. BMC Infect Dis. 2013;13:598.

32. Faye B, Offianan AT, Ndiaye JL, Tine RC, Touré W, Djoman K, et al. Efficacy and tolerability of artesunate-amodiaquine (Camoquin plus) versus artemether-lumefantrine (Coartem) against uncomplicated Plasmodium falciparum malaria: multisite trial in Senegal and Ivory Coast. Trop Med Int Health. 2010;15:608-13.

33. Witkowski B, Amaratunga C, Khim N, Sreng S, Chim P, Kim S, et al. Novel phenotypic assays for the detection of artemisinin-resistant Plasmodium falciparum malaria in Cambodia: in vitro and ex vivo drug-response studies. Lancet Infect Dis. 2013;13:1043-9.

34. Fandeur T. Laboratoire National de Référence pour la surveillance des Chimiorésistances du Paludisme au Niger. 2011; 1-19.

35. Witkowski B, Khim N, Chim P, Kim S, Ke S, Kloeung N, et al. Reduced artemisinin susceptibility of Plasmodium falciparum ring stages in Western Cambodia. Antimicrob Agents Chemother. 2013;57:914-23.

36. Brewer TG, Grate SJ, Peggins JO, Weina PJ, Petras JM, Levine BS, et al. Fatal neurotoxicity of arteether and artemether. Am J Trop Med Hyg. 1994;51:251-9.

37. Huang $X$, Aslanian RG. Case studies in modern drug discovery and development. London: Wiley; 2012

38. Achieng AO, Muiruri P, Ingasia LA, Opot BH, Juma DW, Yeda R, et al. Temporal trends in prevalence of Plasmodium falciparum molecular markers selected for by artemether-lumefantrine treatment in pre-ACT and post-ACT parasites in Western Kenya. Int J Parasitol Drugs Drug Resist. 2015;5:92-9.

39. Sisowath C, Ferreira PE, Bustamante LY, Dahlström S, Mårtensson A, Björkman A, et al. The role of pfmdr 1 in Plasmodium falciparum tolerance to artemether-lumefantrine in Africa. Trop Med Int Health. 2007:12:736-42.

40. Trape JF, Tall A, Sokhna C, Ly AB, Diagne N, Ndiath O, et al. The rise and fall of malaria in a West African rural community, Dielmo, Senegal, from 1990 to 2012: a 22 year longitudinal study. Lancet Infect Dis. 2014:14:476-88

41. Ly O, Gueye PE, Deme AB, Dieng T, Badiane AS, Ahouidi AD, et al. Evolution of the pfcrt T76 and pfmdr 1 Y 86 markers and chloroquine susceptibility 8 years after cessation of chloroquine use in Pikine, Senegal. Parasitol Res. 2012;111:1541-6.

42. Ndiaye M, Faye B, Tine R, Ndiaye JL, Lo A, Abiola A, et al. Assessment of the molecular marker of Plasmodium falciparum chloroquine resistance 
(Pfcrt) in Senegal after several years of chloroquine withdrawal. Am J Trop Med Hyg. 2012;87:640-5.

43. Mouzin E, Thior PM, Diouf MB, Samb B. Focus sur le Senegal. Geneva, Roll Back Malaria. 2010. http://www.rollbackmalaria.org/files/files/resources/ report4-fr.pdf.
44. Pradines B, Tall A, Parzy D, Spiegel A, Fusai T, Hienne R, et al. In-vitro activity of pyronaridine and amodiaquine against African isolates (Senegal) of Plasmodium falciparum in comparison with standard antimalarial agents. J Antimicrob Chemother. 1998;42:333-9.
Submit your next manuscript to BioMed Central and we will help you at every step:

- We accept pre-submission inquiries

- Our selector tool helps you to find the most relevant journal

- We provide round the clock customer support

- Convenient online submission

- Thorough peer review

- Inclusion in PubMed and all major indexing services

- Maximum visibility for your research

Submit your manuscript at www.biomedcentral.com/submit
() Biomed Central 